\title{
Is USG-guided aspiration more effective than physiotherapy in the treatment of Baker's cyst?
}

\author{
๑Nurmuhammet Taş ${ }^{1}$, @Hülya Uzkeser ${ }^{2}$, @Akın Erdal ${ }^{2}$ \\ ${ }^{1}$ Erzurum Regional Education and Research Hospital, Department of Physical Medicine and Rehabilitation, Erzurum, Turkey \\ ${ }^{2}$ University of Ataturk, Department of Physical Medicine and Rehabilitation, Erzurum, Turkey
}

Cite this article as: Bolat A, Gültekin Y. Effectiveness of internal compression therapy in primary safen vein failure. Anatolian Curr Med J 2022; 4(1); 24-28.

\begin{abstract}
Aim: Previous publications have described various therapeutic modalities for symptomatic cysts, including non-steroidal antiinflammatory drugs, cystostomy, physical therapy, and exercises. The objective of thise study was to elucidate the effectiveness of shrinking the cyst without steroidal injection and to compare aspiration with classic physiotherapy and exercises.

Material and Method: This randomized, controlled trial involved 40 patients with Baker's cyst. The participants were randomized into two groups, (I) an aspiration group $(n=20)$ and (II) a control group $(n=20)$. In the aspiration group, Baker's cyst content was aspirated percutaneously under USG guidance, while no aspiration was performed in the control group. Pain was evaluated with a visual analog scale, while the Lysholm knee scoring scale and Cincinnati knee rating system were employed to determine functional status. Quality of life and disability were evaluated using the Nottingham Health Profile and the Western Ontario and McMaster Universities Arthritis Index .

Results: Differences were observed in USG measurements (width, length, and area) and clinical parameters before and after treatment in both groups. However, although these differences were greater in the aspiration group, they were not statistically significant.

Conclusion: Our results indicate that cyst aspiration performed with USG provides no additional effect to those of physical exercises and cold application. Exercise therapy and cold application should be considered before proceeding with an invasive procedure.
\end{abstract}

Keywords: Baker's cyst, cyst aspiration, cold pack, knee exercises, physical therapy, ultrasonography

\section{INTRODUCTION}

Popliteal cysts (PCs) were first described by Adams in 1840. However, after Baker's report of 1877, these cysts were collectively defined as Baker's cyst (BC) (1). There are six bursas around the popliteal fossa in the knee (1), all of which are expandable. The most frequently expanding bursa is the gastrocnemius semimembranosus bursa, also known as the PC or BC (2). Rauschning and Lindgren classified cysts in the popliteal region into two categories $(3,4)$. In case of primary or idiopathic BCs, the cyst has a valvular connection with the joint space. This type of cyst is frequently seen in children and young adults and does not cause joint symptoms. Secondary or symptomatic cysts are directly related to the joint and are often symptomatic.

BCs on the knees in adult patients are often accompanied by an undefined pain and mass behind the knee. Patient also describe complaints related to intra-articular pathologies that are more associated with movement limitation in the knee, particularly during physical activity. At physical examination, the inside of the popliteal region is palpable as a round, smooth-faced, fluctuating mass that becomes apparent during extension and disappears during flexion (Foucher's sign) (5). These position-dependent changes are used for differentiating $\mathrm{BC}$ from other masses.

Ultrasonography (USG) and magnetic resonance imaging (MRI) are used to determine whether a popliteal region mass is solitary or cystic. Previous studies have shown that the diagnostic findings of USG are compatible with those of arthrography (6). USG is particularly valuable in differentiating between popliteal artery aneurysm, venous insufficiency, and solitary masses. MRI is a non-invasive method used for identifying accompanying pathologies, but is expensive and not easily available. 


\section{Study Hypothesis}

Previous publications have described various therapeutic modalities for symptomatic cysts, including non-steroidal anti-inflammatory drugs, cystostomy, physical therapy, and exercises.

Research to date has investigated pain, knee functions, and disability in BC. However, no studies have evaluated all these symptoms (pain, knee functions, and disability) in a single trial. This study was therefore intended to examine these parameters in the same patient population.

The objective of thise study was to determine the effectiveness of shrinking the cyst without steroidal injection and to compare aspiration with classic physiotherapy and exercises.

\section{MATERIAL AND METHOD}

This prospective, randomized study was conducted at the Atatürk University Medical Faculty Department of Physical Therapy and Rehabilitation. This study was carried out with the permission of Atatürk University Faculty of Medicine Clinical Research Ethics Committee (Date: 03.12.2015, Decision No: 08-24). The clinical trial registry number was NCT04785014 (ClinicalTrials.gov Identifier: NCT04785014). Informed consent was obtained from all participants. All procedures were carried out in accordance with the ethical rules and the principles of the Declaration of Helsinki.

\section{Participants}

Forty patients with symptoms of swelling at the back of the knee were included in the study. The sample size was determined with a 95\% confidence interval using the $\mathrm{G}^{\star}$ POWER 3.1.9.7 website. Diagnosis of BC was based on the patient's medical history and USG assessment. All patients were evaluated by means of gray-scale USG using an Esaote MyLab 60 USG device with a linear probe of 7.5 $\mathrm{MHz}$. The transverse diameter (width-parallel to the knee joint), longitudinal, and cyst areas were recalculated at USG examination.

The inclusion criteria were (1) diagnosis of BC confirmed via standard USG evaluation, (2) swelling or tension at palpation of the posterior aspect of the knee at physical examination, and (3) varying degrees of flexion-extension of the knee joint. Patients with (1) a history of malignancy, (2) coagulation disorders, (3) any neurological deficit, (4) receiving anticoagulant therapy, (5 )with a history of previous knee surgery, or with (6) acute local or systemic infections were excluded.

After screening, 40 eligible participants were randomly divided into two groups by consecutive alternate allocation based on time of admission. The aspiration group $(n=20)$ consisted of patients aspirated with USG-guidance, and the control group $(n=20)$ of patients undergoing no aspiration procedure.

\section{Outcome Measures}

Prior to intervention, demographic data including sex, age, body mass index, and the affected side were collected. Pain was evaluated with a visual analog scale (VAS), and Lysholm's knee scoring scale and the Cincinnati knee rating system were employed to determine the functional status of the knee. Quality of life and disability were evaluated using the Nottingham Health Profile (NHP) and the Western Ontario and McMaster Universities Arthritis Index (WOMAC). The NHP is a questionnaire designed to measure the patient's view of his health status. All participants were evaluated before the interventions, and after one and three months.

\section{Intervention}

In the aspirated group, the popliteal fossa areas were sterilized, and BC content was aspirated from the popliteal fossa percutaneously under USG guidance with a 21-gauge needle (Figure 1). If the BC was septal, aspiration was performed from several different levels of the cyst so that the content could be completely emptied. In contrast, no aspiration was performed on the control group. Additionally, the participants in both groups were trained to perform exercises and were also advised to practice cold treatment for $15 \mathrm{~min}$ in the morning and evening for two weeks (wrapping a towel around the knee for $15 \mathrm{~min}$ ).

\section{Exercise Program}

Both groups received exercises including range of motion exercises (extension/flexion), stretching of hamstrings, non-weight bearing exercises for gastrocnemius/soleus, muscle re-education in the form of quadriceps sets, straight leg raise, hip adduction, multiangle isometrics, ankle pumps, and heel slides.

No patient received any additional treatment during the three-month follow-up period. The success of the procedure was defined as a reduction in $\mathrm{BC}$ width, length, and area on sonographic measurements and decreases in the Lysholm knee scoring scale, Cincinnati knee rating system, VAS, WOMAC knee osteoarthritis index, and NHP scores.

\section{Statistical Analysis}

Statistical analysis was performed on Statistical Package for the Social Sciences for Windows version 22.0 software (SPSS,Chicago,IL,USA). Numerical variables were expressed as mean \pm standard deviation. The independent sample t-test was used to compare the ages of the aspirated and non-aspirated groups. The Mann-Whitney $U$ test was applied to compare the genders of the aspirated and non-aspirated groups. One-Way ANOVA for repeated measures was used to determine differences in clinical and ultrasonographic measurements between baseline, and the first, and third-months. p-values $<0.05$ were regarded as statistically significant. 

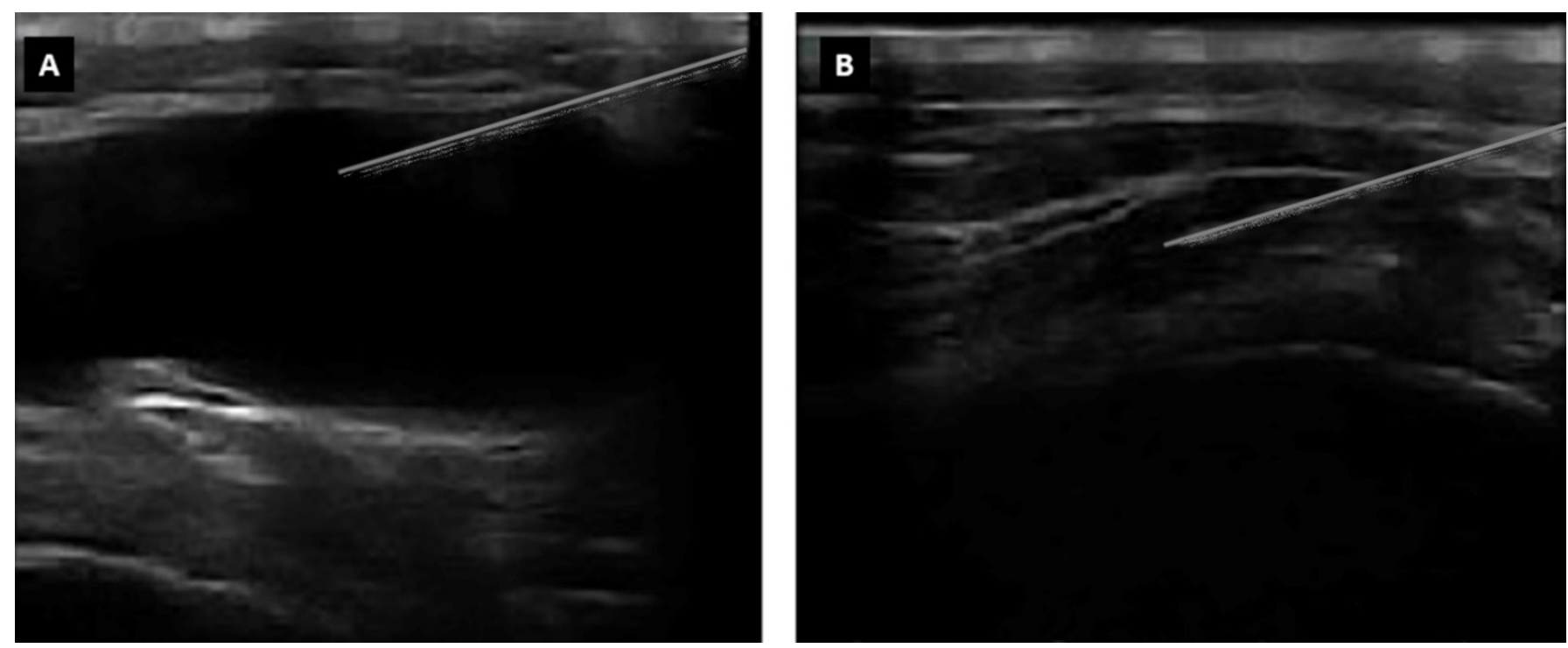

Figure 1. A-USG-guided percutaneous injection into a Baker's cyst, B-Aspiration of the content of a Baker's cyst

\section{RESULTS}

The study involved 40 patients (11 male, 29 female) with a mean age of $55.9 \pm 9.6$ years (Table 1). Initial, BC width was $20.8 \pm 9.1 \mathrm{~mm}$, length was $27.22 \pm 8.8 \mathrm{~mm}$, and area was $455.75 \pm 241.9 \mathrm{~mm}^{2}$ in the aspiration group. Significant differences were observed in both USG measurements (width, length, and area) and clinical parameters in both patient groups on the first and third months. While this difference was greater in the aspiration group, it was not statistically significant in the non-aspiration group. The length of the BC's decreased in both the aspirated and non-aspirated patients (Wilks' Lambda $=0.79$, $\mathrm{F}(2.37)=4.79, \mathrm{p}=0.014)$.

A greater decrease in the length of the cysts was observed in the patients in the aspirated group, but this was not statistically significant (Wilks' Lambda $=0.97$, $\mathrm{F}(2.37)=.414, \mathrm{p}=0.664)$. Similarly, the $\mathrm{BC}$ widths decreased in both the aspirated and non-aspirated patients $(\mathrm{F}(2-76)=11.24, \mathrm{p}=0.000<0.5)$. Although the cyst widths decreased more in the aspirated group, the difference was again not significant $(F(2-76)=.111$, $\mathrm{p}=0.895>0.5)$. $\mathrm{BC}$ areas in the two groups are shown in Table 2. The cyst areas decreased in both groups, but not statistically significantly $(\mathrm{F}(2-76)=.460, \mathrm{p}=0.633>0.5)$. VAS, WOMAC, and NHP scores also decreased in both aspirated and non-aspirated patients (Tables 3 and Table 4). Although the scores decreased more in the aspirated group, this was also not statistically different. Lysholm knee and Cincinnati knee scores increased in both aspirated and non-aspirated patients (Tables 3 and Table 4). Similarly, no significant difference was observed between the two groups in terms of Cincinnati knee scores or Lysholm knee scores.

\section{Table 1. Patients' demographic parameters}

\begin{tabular}{|c|c|c|c|}
\hline & $\begin{array}{c}\text { aspirated } \\
(\text { mean } \pm S D)\end{array}$ & $\begin{array}{c}\text { Non-aspirated } \\
(\text { mean } \pm S D)\end{array}$ & $\mathbf{p}$ \\
\hline Age (year) & $59.55 \pm 8.6$ & $52.25 \pm 9.4$ & $0.015^{\mathrm{a}}$ \\
\hline Gender $(\mathrm{M} / \mathrm{F})$ & $6 / 14$ & $5 / 15$ & $0.73^{\mathrm{b}}$ \\
\hline BMI & $30.61 \pm 3.9$ & $28.49 \pm 3.1$ & $0.07^{\mathrm{a}}$ \\
\hline
\end{tabular}

Table 2. Baker's cyst areas in the two groups

\begin{tabular}{|clccc|}
\hline Area of BC & Groups & mean & SD & N \\
\hline Baseline & & & & \\
& Non-aspirated & 213,1000 & 105,68269 & 20 \\
& aspirated & 455,7500 & 241,92841 & 20 \\
& Total & 334,4250 & 221,47847 & 40 \\
First month & & & \\
& Non-aspirated & 149,6655 & 81,73168 & 20 \\
& aspirated & 352,5000 & 240,75856 & 20 \\
Third month & Total & 251,0828 & 205,04337 & 40 \\
& Non-aspirated & 149,5610 & 99,59434 & 20 \\
& aspirated & 371,1500 & 248,59993 & 20 \\
& Total & 260,3555 & 218,01641 & 40 \\
\hline
\end{tabular}

Table 3. Evaluation of parameters in the aspiration group at baseline, and at the first and third months

\begin{tabular}{|lcccc|}
\hline & $\begin{array}{c}\text { Baseline } \\
(\text { mean } \pm \text { SD })\end{array}$ & $\begin{array}{c}\text { First month } \\
(\text { mean } \pm \text { SD })\end{array}$ & $\begin{array}{c}\text { Third } \\
\text { month } \\
(\text { mean } \pm \text { SD })\end{array}$ & p \\
\hline $\begin{array}{l}\text { VAS } \\
\begin{array}{l}\text { Lysholm } \\
\text { knee } \\
\text { scoring } \\
\text { scale, }\end{array}\end{array}$ & $7.3 \pm 1.8$ & $5.5 \pm 2.5$ & $5.5 \pm 2.9$ & $.001<\mathrm{p}(.493)$ \\
$\begin{array}{l}\text { Cincinnati } \\
\text { knee rating } \\
\text { system, }\end{array}$ & $10.4 \pm 7.2$ & $14.6 \pm 8.6$ & $15.8 \pm 8.3$ & $.001<\mathrm{p}(.121)$ \\
$\begin{array}{l}\text { NHP } \\
\text { scores. }\end{array}$ & $206.6 \pm 92.8$ & $146.2 \pm 95.3$ & $139.2 \pm 96.6$ & $.001<\mathrm{p}(.273)$ \\
WOMAC & $68.3 \pm 18.1$ & $51.2 \pm 29.3$ & $48.6 \pm 27.3$ & $.001<\mathrm{p}(.219)$ \\
\hline
\end{tabular}




\begin{tabular}{|c|c|c|c|c|}
\hline & $\begin{array}{c}\text { Baseline, } \\
(\text { mean } \pm S D)\end{array}$ & $\begin{array}{l}\text { First month } \\
(\text { mean } \pm \text { SD })\end{array}$ & $\begin{array}{l}\text { Third month } \\
\text { (mean } \pm \text { SD) }\end{array}$ & $\mathbf{p}$ \\
\hline VAS & $5.2 \pm 2.4$ & $3.9 \pm 2.8$ & $4.3 \pm 2.9$ & $\mathrm{p}<.001(.000)$ \\
\hline $\begin{array}{l}\text { NHP } \\
\text { scores }\end{array}$ & $202.4 \pm 98.9$ & $170.9 \pm 88.9$ & $139.7 \pm 75.3$ & $\mathrm{p}<.001(.000)$ \\
\hline WOMAC & $53.2 \pm 24.5$ & $49.3 \pm 28.6$ & $46.1 \pm 26.1$ & $.001<\mathrm{p}(.009)$ \\
\hline $\begin{array}{l}\text { Lysholm } \\
\text { knee } \\
\text { scoring } \\
\text { scale, }\end{array}$ & $61.6 \pm 17.2$ & $68.6 \pm 16.8$ & $69.9 \pm 17.6$ & $\mathrm{p}<.001(.000)$ \\
\hline $\begin{array}{l}\text { Cincinnati } \\
\text { knee rating } \\
\text { system, }\end{array}$ & $14.5 \pm 9.2$ & $15.9 \pm 8.9$ & $17.6 \pm 7.7$ & $\mathrm{p}<.001(.000)$ \\
\hline
\end{tabular}

\section{DISCUSSION}

Synovial effusion in osteoarthritis (OA) and other intraarticular pathologies leads to an increase in intracavitary pressure, the first phase of the mechanism involved in $\mathrm{BC}$ formation (7). BC is a fluid-filled mass representing a distention of a pre-existing bursa in the popliteal fossa, most commonly the gastrocnemius-semimembranosus bursa. In contrast to other known periarticular bursae, this bursa is unique in that it communicates with the knee joint through an opening in the joint capsule behind the medial femoral condyle. This opening may create a valve-like mechanism in the presence of effusion. This mechanism may thus lead to the formation of these cysts in adults.

Numerous therapeutic options have been reported for popliteal cysts, particularly considering the underlying cause and associated conditions (8-14). Asymptomatic $\mathrm{BCs}$ and incidentally located cysts do not require any treatment. However, aspiration of the knee joint may be useful in the presence of knee effusion. Acebes et al. evaluated the sonographic changes occurring in $\mathrm{BC}$ after single intra-articular corticosteroid injection in patients with OA of the knee accompanied by BC. The authors concluded that USG is an ideal imaging method, not only in the diagnosis of $\mathrm{BC}$ but also in the evaluation of the response to treatment (7). USG was employed in the present study, since it provides procedural safety and also it is non-invasive, inexpensive, and easily accessible.

Many cases of relapse after treatment as well as successful steroid injection have been published in the literature (15). These relapses were mostly explained in terms of cysts possibly having a complex structure. Hypothesizing that aspiration alone may perhaps be sufficient, this study was intended to determine whether aspiration can be superior to conventional cold therapy and exercises.

Cold pack and exercise methods are more non-invasive and should be applied initially since they are easier for use by a physician. Cold pack therapy is a nonpharmacological method used in musculoskeletal injuries and many surgical procedures. Cold therapy produces its effect primarily by removing heat energy conduction from the injury site (16). Cold therapy produces effects such as a decrease in blood flow, reductions in edema and hemorrhage, hypoxia, a decrease in enzymatic activity, and tissue damage (17). It has also been demonstrated to significantly increase the pain threshold and pain tolerance by reducing nerve conduction velocity and muscle spasm (18). No additional drug therapy was given to our study groups, and the study design was thus unaffected.

Calvisi et al. (19) suggested that arthroscopic surgery is an effective method in the treatment of cysts and related joint diseases. That study evaluated 22 patients with BC associated with intra-articular pathologies. Over the two-year follow-up period, clinical improvement was achieved in $96 \%$ of patients, $64 \%$ of cysts disappeared on MRI, $27 \%$ of cysts were in remission, and $9 \%$ of cysts persisted. The authors concluded that arthroscopic techniques can improve BC-related symptomatology and may lead to complete loss or shrinkage of the cyst. The participants in our study were not complicated by intraarticular knee pathologies. However, surgical treatment may be considered in case of $\mathrm{BC}$ accompanied by intraarticular knee pathologies that require surgery, such as meniscus tears and anterior cruciate ligament tears.

Previous studies have generally used only one additional questionnaire together with VAS scores. The present study yielded a more objective evaluation by using scales that had previously been employed separately. Complaints, limitations, functional movements, and quality of life were all assessed. This resulted in a more objective approach to the patients, since rehabilitation involves approaching the patient an integral whole.

\section{CONCLUSION}

Cyst aspiration is an invasive procedure. Our results indicate that cyst aspiration performed with USG provides no additional effect to those of physical exercises and cold application. Exercise therapy and cold application should therefore be considered before proceeding with an invasive procedure.

\section{ETHICAL DECLARATIONS}

Ethics Committee Approval: This study was carried out with the permission of Atatürk University Faculty of Medicine Clinical Research Ethics Committee (Date: 03.12.2015, Decision No: 08-24).

Informed Consent: All patients signed the free and informed consent form.

Referee Evaluation Process: Externally peer-reviewed. 
Conflict of Interest Statement: The authors have no conflicts of interest to declare.

Financial Disclosure: The authors declared that this study has received no financial support.

Author Contributions: All of the authors declare that they have all participated in the design, execution, and analysis of the paper, and that they have approved the final version.

\section{REFERENCES}

1. Handy JR. Popliteal cysts in adults: a review. Semin Arthritis Rheum 2001; 31: 108-18.

2. Baker WM. On the formation of synovial cysts in the leg in connection with disease of the knee-joint. 1877.Clin Orthop Relat Res 1994; 299: 2-10.

3. Burleson RJ, Bickel WH, Dahlin DC. Popliteal cyst; a clinicopathological survey. J Bone Joint Surg Am 1956; 38-A: 1265-74.

4. Gristina AG, Wilson PD. Popliteal cysts in adults and children. a review of 90 cases. Arch Surg 1964; 88: 357-63.

5. Canoso JJ, Goldsmith MR, Gerzof SG, Wohlgethan JR. Foucher's sign of the Baker's cyst. Ann Rheum Dis 1987; 46: 228-32.

6. Scheible W. Diagnostic ultrasound. In: Diagnosis of bone and joint disorders ( $2^{\text {nd }}$ ed) Resnick D, Niwa-yama G, eds. Phildelphia Saunders 1988; 1: 247-9

7. Acebes JC, Sanchez-Pernaute O, Diaz-Oca A, Herrero-Beaumont G. Ultrasonographic assessment of Baker's cysts after intraarticular corticosteroid injection in knee osteoarthritis. J Clin Ultrasound 2006; 34: 113-7.

8. Good AE. Rheumatoid arthritis, Baker's cyst, and "thrombophlebitis". Arthritis Rheum 1964; 7: 56-64.

9. Macfarlane DG, Bacon PA. Popliteal cyst rupture in normal knee joints. Br Med J 1980; 281: 1203-4.

10. Takano Y, Oida K, Kohri Y, et al. Is Baker's cyst a risk factor for pulmonary embolism? Intern Med 1996; 35: 886-9.

11. Kirkham B, Churchill M, Dasgupta B, Wedderburn L, Spencer J, Macfarlane DG. Anterolateral rupture of popliteal cysts in rheumatoid arthritis. Ann Rheum Dis 1991; 50: 187-8.

12. Dash S, Bheemreddy SR, Tiku ML. Posterior tibial neuropathy from ruptured Baker's cyst. Semin Arthritis Rheum 1998; 27: 272-6.

13. Scott WN, Jacobs B, Lockshin MD. Posterior compartment syndrome resulting from a dissecting popliteal cyst. Case report. Clin Orthop Relat Res 1977; 122: 189-92.

14. Nakano KK. Entrapment neuropathy from Baker's cyst. JAMA 1978; 239: 135.

15. Köroglu M, Callıglu M, Eris HN, et al. Ultrasound-guided percutaneous treatment and follow-up of Baker's cyst in knee osteoarthritis. Eur J Radiol 2012; 81: 3466-71.

16. Cooling efficiency of 4 common cryotherapeutic agents. J Athl Train 2007; 42: 343-8.

17. Cina-Tschumi B. (Evidence-based impact of cryotherapy on postoperative pain, swelling, drainage, and tolerance after orthopedic surgery). Pflege 2007; 20: 258-67.

18. Algafly AA, George KP. The effect of cryotherapy on nerve conduction velocity, pain threshold and pain tolerance. $\mathrm{Br} \mathrm{J}$ Sports Med 2007; 41: 365-9.

19. Calvisi V, Lupparelli S, Giuliani P. Arthroscopic all-inside suture of symptomatic Baker's cysts: a technical option for surgical treatment in adults. Knee Surg Sports Traumatol Arthrosc 2007; 15: 1452-60. 